\author{
Nyssanbayeva G., Tursunbek S., Kudaibergenov K., \\ Ongarbayev Ye., Mansurov Z., Lubchik S. \\ Al-Farabi Kazakh National University, Almaty, Kazakhstan \\ E-mail: kenes19851911@gmail.com
}

\title{
Synthesis and study of physical-chemical properties of expanded graphite
}

\begin{abstract}
One a of the most urgent problems in the field of ecological status assessment is developing of a single integral approach to the problem of environmental quality and, in particular, of water as well as the evaluation criteria of their quality.

In this study, natural graphite is converted to adsorbent, intended for the use in getting rid of oil stains. The microstructure and morphology of expanded graphite made of antitermal natural graphite were investigated by Raman spectroscopy and scanning electron microscope (SEM).

Innovative terminative process was discovered and investigated in the systems «graphite - reactantoxidant» - it is a direct oxidative conversion of graphite in TWG going through the sig formation of as unstable intermediate reactions thermolysis.

The study of graphite's as sorbents of oil in Kazakh science and technology is very relevant and has will be used in future.
\end{abstract}

Key words: expanded graphite, compounds of graphite intercalcination, thermal destruction, carbon plane.

\section{Introduction}

Compounds of intern calcination of graphite (SIG) obtained in the reactions of graphite with acids and oxidizers have been attracting attention of scientists and practitioners for over 150 years [1-3]. This growing interest is caused by the unique ability of SIG in to increase its volume hundreds of times when heated as well aspractical value of the obtained product - thermografenit (TWG) $[1,2]$. High heat resistance, chemical inertness and incombustibility as well as the ability to be compressed without a binder in the carbon products of any form have led to the widespread use of TRH and its products in fire-prevention defense, metallurgy, power industry, aerospace engineering and automotive industry worldwide [4-7].

Practical orientation to the TWG and its products production led to the preferential study of the properties of TRH and improving of its technical characteristics. At the same time, issues connected with kinetics and specific mechanisms of thermal destruction of and formation of TWG have not been studied. The main routes of the thermal destruction of SIG are considered on a qualitative level, quantitative description of the thermal destruction process is performed for the most simple systems.

This situation has led to the fact that the process of obtaining of the TWG is considered only technologically two-staged (obtaining of an intermediate product SIG and final product - TWG), the management of this process is transferred to the area of synthesis of SIG. When the fruitfulness of this approach excludes the question of technologically one-step receipt of TWG and thus greatly restricts the use of thermolysis reactions in systems of «graphite - reactant-oxidant» for the synthesis of TRH having desired properties.

It is obvious that the processes of thermolysis are far from exhausted, and new theoretical and practical approaches to the process of obtaining of TWG may be offered on the basis of data about the mechanism of conversion of graphite into systems «graphite - reactant-oxidant» [3-5]. The performed studies are an attempt to mut the specified lack, and to consider the synthesis process of SIG and its thermal destruction to the TWG as a single process of the direct oxidative conversion of graphite in TWG.

The objective of the work is synthesis and study of physico-chemical properties of expanded graphite. 


\section{Experimental part}

Physical-chemical properties of the samples are determined in the laboratory of physical and chemical research, as well as in the a National nanotechnological laboratory of an open type. al-Farabi: KazNU their macrostructure is defined by various methods of physical chemical analysis.

In order to make the study the original substances and some inorganic salts were used: such as natural graphite, barium nitrate and iron chloride. Natural flake graphite brand,such as GL-1 and GT-2were used. The part of graphite was demineralized in order to eliminate the influence of mineral components on the thermal processes at elevated temperatures.

Demineralization included processing of $5 \% \mathrm{HCl}$ (heated for $1.5 \mathrm{~h}$ in boiling water bath at a ratio of $4 \mathrm{dm} 3 \mathrm{HCl}: 1 \mathrm{~kg}$ of graphite), filtration, washing out with $0.5 \%$ of $\mathrm{HC}$, processing of $20 \% \mathrm{HF}\left(60^{\circ} \mathrm{C}, 3\right.$ h). filtration, washing out with water til neutral reaction and bringing to air dry condilion the at room temperature. The ash content of the demineralized sample is $<0.5 \%$.

The entering of salts was carried out by the dry method: mechanical mixture of graphite with salts in a molar ratio of graphite:salt $-62,5: 1 ; 33,3: 1 ; 19: 1$; $6,4: 1 ; 2,7: 1$. and method of impregnation: $0.6 \mathrm{~g}$ of graphite were moistened to $0.8 \mathrm{~cm} 3$ by aqueous solutions of different salt concentrations: 0,$41 ; 1.24$; 2,$07 ; 3,33 ; 4,6(\mathrm{M})$ and brought to air dry state at room temperature and of was periodically stirring. Then the samples were dried for $2 \mathrm{~h}$ at $105 \pm 2{ }^{\circ} \mathrm{C}$. The Samples were systems «graphite - salt» in molar ratio $119: 1 ; 54: 1 ; 30: 1 ; 18: 1 ; 12: 1$

Kinetic studies of thermal destruction of SIG in isothermal mode were performed in thermoweightl installation (Fig. 1), which is running on gas, the reactor (1) has the evaporator coil (2). The reactor with the evaporator are arranged in the air chamber of the thermostat (3) (accuracy of temperature control $\left.\pm 1^{\circ} \mathrm{C}\right)$.

To create a uniform upward flow of gases and vapors inside the reactor (1) a porous glass septum is soldered (4). Measurement of loss of mass was performed using a torsion balance (5) with measuring range of 0 to $250 \mathrm{mg}$.

Hitch SIG (50-100 mg) was placed into a specially designed crucible (6) with a cover $(\mathrm{d}=12 \mathrm{~mm}$, height $10 \mathrm{~mm}$ ), suspended to the yoke of weights using a Teflon thread. Measurement error of the mass does not exceed of $\pm 2 \times 10-4 \mathrm{~g}$. Measure ment of the mass loss of the samples was performed in air medium.

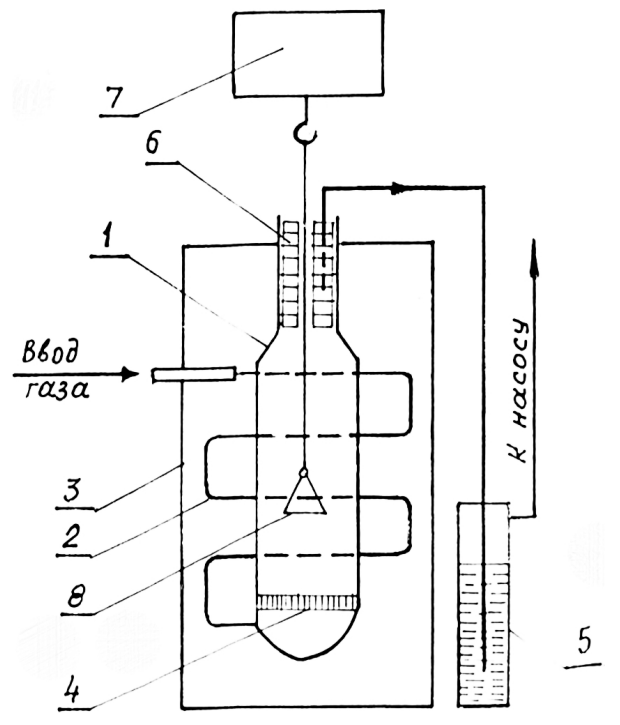

Figure 1 - Schematic diagram thermovisual installation

1) glass reactor; 2) the evaporator coil; 3 ) thermostat; 4) porous glass partition; 5) converter of gases; 6) the mixer; 7) torsion scales; 8) measuring cell

\section{Results and their Discussion}

From the results of electron-microscopic examination, one can see that the natural graphite is composed of thin layers of a thickness of $80 \mathrm{~nm}$. These layers have a high degree of crystallinity.

Electronic microscopic analysis showed that the natural graphite impregnated with a solution of barium nitrate has macropores (Figure 1b). Metal containing phase is unevenly distributed on the surface expanded graphite matrix. The shape of the particles GHG is determined by the layered structure of graphite and foaming occurs in one direction only, namely, perpendicularly to the stacking of layers, particle penografia becomes of a worm-shaped form. Color of expanded graphite is from ash-grey to black without typical for initial graphite metallic shine. The chemical composition of expanded graphite represents the carbon like the initial graphite, however, the level of impurities in $\mathrm{PG}$ is much higher than for the original material. As one of the aims of the present work was the doping of penografia by metalic compounds; then IG, modified by nitrates of metals (IG(IU)), is to be the best precursor. Getting of penografia, doped by metal oxides, will be already possible at $850^{\circ} \mathrm{C}$, i.e. at the temperature of decomposition of barium nitrate.

Produced samples were also investigated by Raman spectroscopy. We can see from the spectra that all samples have carbon structure. 


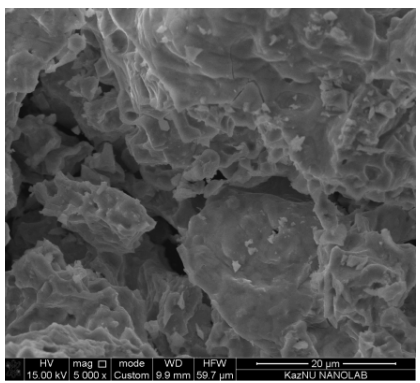

a)

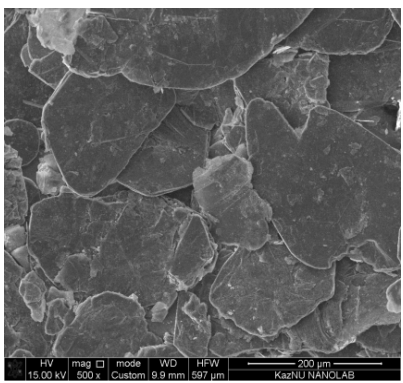

b)

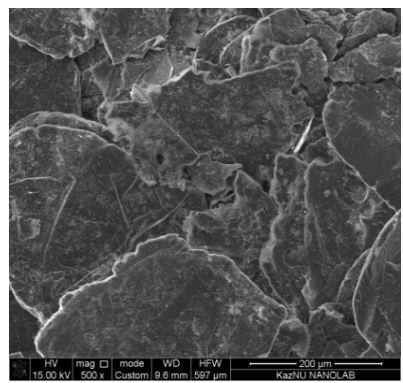

c)

Figure 1 - SEM images: (a) natural graphite, (b) graphite impregnated with salts $\mathrm{FeCl}_{3}$; (c) modified graphite with barium nitrate

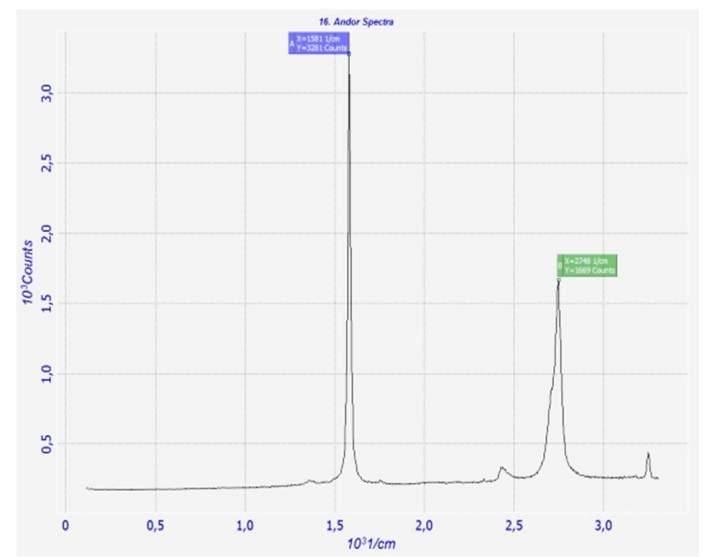

a)

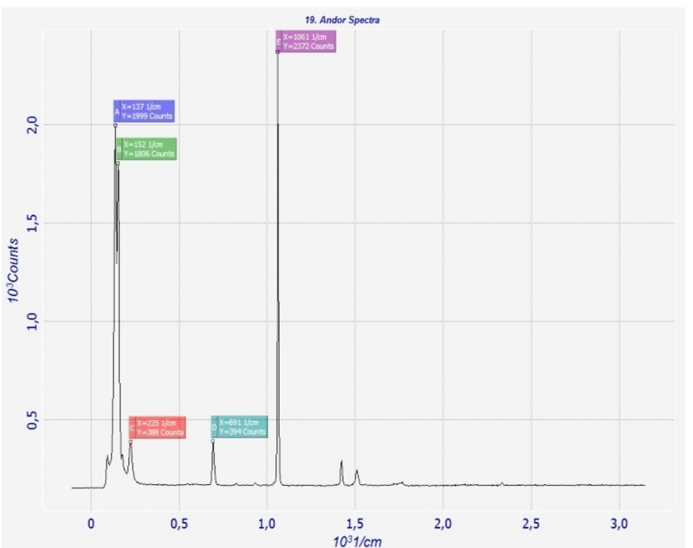

b)

Figure 2 - Raman spectra of: (a) natural graphite, (b) graphite impregnated with salts of $\mathrm{BaNO}_{3}$

Further analysis of the sample the structure of the original and heat-treated graphite was performed by the method of Raman scattering (RS). For the excitation of spectra a semiconductor laser emitting a wavelength of 532 $\mathrm{nm}$ was used. The study was carried out at the room temperature. The analysis of spectra of Raman scattering of graphite sample revealed the presence of several lines of cattle; Line A of about $1581 \mathrm{~cm}-1$, peak B of about $2748 \mathrm{1} /$ $\mathrm{cm}$. Lines of about of $1581 \mathrm{~cm}-1$, as belonging to the defects on the edges of the plots ideal carbon planes.

In the spectra of heat-treated graphite several different peaks appeared, which indicate different planes. Line A-1371 cm-1, peak B-1521 cm1, peak C-225 cm-1, peak D-691 $1 / \mathrm{cm}$, and the line E 1061-cm-1. Carbon is linked in flat sheets, similar to the planes in graphite. Such a conclusion can be made on the basis of the complete absence of a peak- $1350 \mathrm{~cm} 1$ in the spectrum, in the presence of intense and narrow line of about $1575 \mathrm{~cm}-1$. It says that the vast majority of carbon atoms are in the sp2 state and form wellshaped flat structures. The presence of lines C and $\mathrm{D}$ is characteristic for graphite having a high degree of order.

Thus the obtained results show that heattreated graphite has an almost perfect crystalline structure of graphite.

For the formation of intercalation compounds of graphite with the chlorides of metals mechanism involving the direct participation of chlorine in the process of internalrevenue is suggested.

In the gas phase chlorine molecules are adsorbed on graphite, then the chlorine is transferred to the atomic state and oxidizes the graphite matrix to form microcation CP. Electroneutrality is supported by adsorbed SG. Molecules of the metal chloride diffuse in-charged graphite matrix, to capture the anions of chlorine give the compound of electroneutrality, and an embedded layer in ISH with chlorides of metals 
represents a chlorine anions surrounded by neutral molecules of the metal chloride.

The phase composition of GHGs regardless of the temperature of foaming represented by graphite-at the interlayer distance of $3.36 \mathrm{~A}^{\circ}$. The yield of a solid product is within the limits of $80-94 \%$ and shows once again that the chemical processing with the subsequent foaming is accompanied by the partial transfer of carbon to carbon dioxide. The yield of carbon at $900^{\circ} \mathrm{C}$ in the process of obtaining chemically-modified expanded graphite is $92-95 \%$.

Table 1 shows the basic characteristics of natural graphite of grade GL-1 and GT-2. As the table shows, the specific surface of natural graphite of grade GL-1 and GT-2 is 6,382 and $9,546 \mathrm{~m} 2 / \mathrm{g}$, respectively. The highest amount of carbon is $\sim 92 \%$ for natural graphite.

Table 1 - Main characteristics of natural graphite

\begin{tabular}{|c|c|c|c|c|c|}
\hline Samples & $\begin{array}{c}\text { Carbon } \\
\text { content, } \%\end{array}$ & $\begin{array}{c}\text { Size of } \\
\text { particles, } \mathrm{mm}\end{array}$ & $\begin{array}{c}\text { Mass fraction of } \\
\text { moisture, } \%\end{array}$ & $\begin{array}{c}\text { Specific } \\
\text { surface, } \mathrm{m}^{2} / \mathrm{g}\end{array}$ & Mass of ash, \% \\
\hline Natural graphite of GL-1 brand & $\sim 92$ & $\sim 0,5$ & 1,0 & 6,382 & 10 \\
\hline Natural graphite of GL-2 brand & $\sim 95$ & $\sim 0,5$ & 0,8 & 4,546 & 7 \\
\hline
\end{tabular}

For the formation of intercalation compounds of graphite with chlorides of metals a mechanism involving the direct participation of chlorine in the process of inter calcinations is suggested.

The thermodynamic conditions of the process of direct oxidative conversion of graphite in TWG considered. Its place in a number of known processes for the synthesis of SIG and its transformation in TWG for «graphite - reactant-oxidant»system is determined.

\section{References}

1. Wbellode A.R., Lewis F.A., Graphite and his crystalline Connections, M.: Mir, 1965, 265 p.(in Russ)

2. Enoki T., Suzuki M., and Endo M., Graphite Intercalation Compounds and Applications Book, Oxford University Press (USA), 27 March 2003, 456
Pages ISBN:9780195128277.(in English)

3. Fischer J.E., Thompson T.E., 2008, Doi: http://dx.doi.org/10.1063/1.2995104. (in English)

4. Yoon G., Seo D., Ku K., Kim J., Jeon S., and Kang K., Chem. Mater., 2015, pp 2067-2073; DOI: $10.1021 / \mathrm{cm} 504511 \mathrm{~b}$. (in English)

5. Rangappa D., Sone K., Wang M., Gautam U., Gilberg D., Iton H., Ichihara M., Honma I., A European Journal, Vol 16,N 22, 2010, pp. 6488-6494. (in English)

6. Cai M., Thorpe D., Adamson D.H., and Schniepp H. C., J.Am. Chem Mater, 2012,Vol. 22, pp. 24992-25002; DOI:10.1039/C2JM34517J. (in English)

7. Parvez K., Wu Z.S., Li R., Liu X., Graf R., Feng X. and Müllen K. J.Am. Chem. Soc, 2014, Vol. 136 , N16, pp 6083-6091; DOI: 10.1021/ja50171567(in English) 